\title{
FAKTOR DURASI MENDERITA DM TIPE 2 MEMPENGARUHI PERUBAHAN KEMAMPUAN EFIKASI DIRI
}

\section{[DURATION FACTORS OF SUFFERING WITH TYPE 2 DM AFFECT CHANGES IN SELF EFFICIENCY ABILITY]}

\author{
Nurul Kartika Sari ${ }^{1}$, Rivan Firdaus ${ }^{2}$ \\ Jurusan Keperawatan Poltekkes Kemenkes Sorong ${ }^{1}$ \\ Jurusan Keperawatan Poltekkes Kemenkes Kaltim² \\ e-mail : ns.nurulkartikasari@gmail.com
}

\section{ABSTRAK}

ABSTRACT
Latar belakang : kasus Diabetes Melitus (DM) meningkat sebanyak 776 Kasus dari tahun sebelumnya berdasarkan data dari RSUD Abdul Wahab Sjahranie. Banyak perubahan yang terjadi dalam hidup penderita DM tipe 2 seperti stress, cemas, marah, dan merasa tidak berguna. Masalah-masalah tersebut dapat diminimalisasikan jika pasien juga memiliki pengetahuan dan kemampuan serta bagaimana efikasi diri yang baik untuk mengelola penyakit dengan cara melakukan perawatan mandiri. Tujuan: Menganalisa faktor yang berhubungan dengan efikasi diri pasien DM tipe 2. Metode: Penelitian kuantitatif dengan pendekatan cross sectional. Teknik sampling purposive pada pasien DM Tipe 2 di RSUD Abdul Wahab Sjahranie Samarinda sesebesar 60 responden periode September-Oktober 2018. Hasil: terdapat hubungan yang signifikan antara lama menderita dengan efikasi diri pasien DM dengana nilai $p<0.001$, dan tidak terdapat hubungan yang signifikan antara usia, jenis kelamin, tingkat pendidikan, pengetahuan, motivasi dengan efikasi diri dengana nilai $p>0.001$. Kesimpulan: Faktor lama menderita DM berhubungan dengan efikasi diri pasien DM Tipe 2

Kata Kunci: Efikasi Diri; Lama Menderita; DM Tipe 2

Background: Diabetes Mellitus (DM) cases increased by 776 cases from the previous year based on data from Abdul Wahab Sjahranie Regional Hospital. There are many changes that occur in the life of people with type 2 diabetes, such as stress, anxiety, anger, and 
feeling useless. These problems can be minimized if the patient also has the knowledge and ability as well as good self-efficacy to manage the disease by doing self-care. Aim: To analyze the factors associated with the self-efficacy of type 2 DM patients. Methods: a quantitative study with a cross sectional approach. The purposive sampling technique for Type 2 DM patients at Abdul Wahab Sjahranie Hospital Samarinda, totaling 60 respondents from September-October 2018. Results: showed significant relationship between duration of suffering and self-efficacy of DM patients with a $p$ value $<0.001$, and there was no significant relationship between age, sex, education level, knowledge, motivation and self-efficacy with a $p$ value $>0.001$. Conclution: The duration of type 2 diabetes is related to the patient's self-efficacy ability.

Key Words: Self Efficacy; Long Suffering; DM Type 2

\section{PENDAHULUAN}

Diabetes mellitus (DM) merupakan penyakit tidak menular khususnya gangguan metabolik yang timbul pada individu ditandai dengan tingginya kadar glukosa darah (hiperglikemia) disebabkan kelainan sekresi insulin, kerja insulin, atau keduanya (American Diabetes Assosiation, 2004 dalam Smeltzer \& Bare, 2008). DM terklasifikasi menjadi DM tipe 1, DM tipe 2, gestasional dibetes dan diabetes tipe lainnya (Black\& Hawk, 2009; deWilt \& Kumagai; Price \& Wilson, 2005).

Beragam jenis makanan jajanan di Indonesia berkembang sangat pesat seiring dengan pesatnya pembangunan. Makanan jajanan didefinisikan sebagai makanan siap makan atau makanan yang bisa langsung dikonsumsi di lokasi jualan, jalanan, atau tempat umum, seperti area pemukiman, pusat perbelanjaan, sekolah atau dijajakan secara berkeliling. Beberapa keunggulan makanan jajanan adalah harganya murah dan mudah didapat, cita rasanya yang enak 
dan cocok dengan selera kebanyakan masyarakat (Iklima, 2017). Hal

itulah yang menjadikan alasan anak-anak usia sekolah khususnya usia Sekolah Dasar sangat menggemari makanan jajanan.

Di masa mendatang penderita DM akan meningkat jumlahnya dan menjadi salah satu ancaman utama bagi kesehatan umat manusia (Suyono, 2010). Hasil Riset Kesehatan Dasar (RISKESDA) tahun 2013, penyakit DM tipe 2 di Indonesia meningkat dari 1,1\% pada tahun 2007 menjadi 2,1\% dari jumlah penduduk di tahun 2013. Berdasarkan studi pendahuluan yang dilakukan di RSUD Abdul Wahab Sjahranie tercatat jumlah pasien DM pada tahun 2017 sebanyak 776 Kasus meningkat lebih tinggi daripada tahun sebelumnya.

Banyak perubahan yang terjadi dalam hidup penderita DM tipe 2 dimulai dari kebiasaan hidup dalam upaya mengontrol gula darah, aktivitas fisik, konsumsi obat, dan diet yang harus dilakukan secara rutin. Perubahan hidup tersebut menghasilkan reaksi psikologis yang negatif seperti stress, cemas, marah, dan merasa tidak berguna. Reaksi psikologis yang sering terjadi pada penderita DM adalah stress (Maghfirah dkk, 2015). Masalah-masalah tersebut dapat diminimalisasikan jika pasien juga memiliki pengetahuan dan kemampuan serta bagaimana efikasi diri yang baik untuk mengelola penyakit dengan cara melakukan perawatan mandiri.

Pengetahuan pasien tentang penyakit DM yang rendah dapat mempengaruhi persepsi pasien tentang penyakitnya, motivasi, manajemen koping dan perubahan perilaku (Sousa \& Zaeseniewski, 
2005). Hasil penelitian menunjukkan bahwa lebih dari 50\% pasien

DM memiliki pengetahuan dan ketrampilan perawatan diri yang rendah sebelum diberikan pendidikan diabetes (Atak, Gurkan \& Kose, 2008). Pengetahuan yang rendah dapat menyebabkan efikasi diri yang rendah dalam perawatan DM (Bernal, Woolley, Schensul \& Dickinson, 2000).

Perspektif pasien DM akan pentingnya efikasi diri diperlukan untuk mencapai tujuan yang diinginkan. Efikasi diri (Self Efficacy) menurut Bandura (1997) adalah keyakinan individu dalam menilai kemampuan dirinya untuk melakukan suatu tindakan. Keyakinan ini meliputi kepercayaan diri, kemampuan menyesuaikan diri, kapasitas kognitif, kecerdasan dan kapasitas bertindak pada situasi yang penuh tekanan. Efikasi diri mempengaruhi bagaimana seseorang berpikir, merasa, memotivasi diri sendiri dan bertindak. Efikasi diri mendorong proses kontrol diri untuk mempertahankan perilaku yang dibutuhkan dalam mengelola perawatan diri pada pasien DM.

Dari hasil wawancara pada pasien yang dirawat di RSUD Abdul Wahab Sjahranie Samarinda didapatkan keluhan psikologis yang banyak dirasakan pasien, yaitu pasien mengeluh cemas atas penyembuhan penyakit, pasien mengalami ketergantungan perawatan diri, dan pasien mengatakan ketakutan dengan dirinya. Adanya peningkatan kasus DM tipe 2 dan munculnya keluhan psikologis seperti uraian diatas, maka peningkatan keyakinan diri dan pemahaman pasien perlu ditingkatkan. 


\section{METODE PENELITIAN}

Berdasarkan latar belakang diatas maka peneliti tertarik melakukan penelitian analisis faktor-faktor yang berhubungan dengan efikasi diri pasien DM tipe 2 di RSUD Abdul Wahab Sjahranie mengingat masih tingginya kasus DM tipe 2.

Desain penelitian ini adalah cross sectional karena ingin melihat hubungan antara faktor demografi dan motivasi dengan efikasi diri pasien DM tipe 2 dalam satu kali pengukuran dengan menggunakan kuesioner. Subjek penelitian dilakukan random cara non probability sampling dengan metode purposive sampling. Penelitian ini terdiri dari variabel bebas (usia, jenis kelamin, lama menderita DM, tingkat pendidikan, pengetahuan dan motivasi) dan variabel tergantung (efikasi diri pasien DM tipe 2).

Total sampel berjumlah 60 orang menggunakan cara Rule of Thumb. Data yang dikumpulkan meliputi karakteristik responden, pengetahuan, motivasi dan efikasi diri yang dikumpulkan menggunakan lembar kuisioner. Pengambilan data dilakukan SUD Abdul Wahab Sjahranie Samarinda selama satu hari dengan pengukuran pada hari yang sama, sambil memperhatikan prinsip etik beneficence, respect for human dignity dan justice. Analisis data menggunakan uji chi-square.

\section{Pengumpulan data pada penelitian ini dapat dilihat dari tabel} berikut ini:

1. Karakteristik responden berdasarkan usia, jenis kelamin, lama menderita, tingkat pendidikan, pengetahuan, motivasi, dan efikasi diri. 
Tabel 1 Distribusi Responden Berdasarkan Usia, Jenis Kelamin, Lama Menderita, Tingkat Pendidikan, Pengetahuan, Motivasi dan Efikasi Diri Pasien DM Tipe 2 di RSUD A.W. Sjahranie Samarinda $(n=60)$

\begin{tabular}{|c|c|c|}
\hline & Jumlah & Persentase \\
\hline Variabel & $\mathrm{n}$ & $\%$ \\
\hline \multicolumn{3}{|l|}{ Usia } \\
\hline$<56$ tahun & 33 & 55 \\
\hline$\geq 56$ tahun & 27 & 45 \\
\hline Total & 60 & 100 \\
\hline \multicolumn{3}{|l|}{ Jenis Kelamin } \\
\hline Laki-laki & 23 & 38,3 \\
\hline Perempuan & 37 & 61,7 \\
\hline Total & 60 & 100 \\
\hline \multicolumn{3}{|c|}{ Lama Menderita DM } \\
\hline$\geq 9$ tahun & 17 & 28,3 \\
\hline$<9$ tahun & 43 & 71,7 \\
\hline Total & 60 & 100 \\
\hline \multicolumn{3}{|c|}{ Tingkat Pendidikan } \\
\hline Tinggi & 4 & 6,7 \\
\hline Rendah & 56 & 93,3 \\
\hline Total & 60 & 100 \\
\hline \multicolumn{3}{|l|}{ Pengetahuan } \\
\hline Kurang & 43 & 71,1 \\
\hline Baik & 17 & 28,3 \\
\hline Total & 60 & 100 \\
\hline \multicolumn{3}{|l|}{ Motivasi } \\
\hline Kurang & 23 & 38,3 \\
\hline Baik & 37 & 61,7 \\
\hline Total & 60 & 100 \\
\hline \multicolumn{3}{|l|}{ Efikasi Diri } \\
\hline Kurang & 31 & 51,7 \\
\hline Baik & 29 & 48,3 \\
\hline Total & 60 & 100 \\
\hline
\end{tabular}

Karakteristik usia kurang dari 56 tahun yakni sebesar 33 responden (55\%). Jenis kelamin perempuan sebanyak 37 responden $(61,7 \%)$. Lama menderita diabetes mellitus $<9$ tahun sebanyak 43 responden $(71,7 \%)$. Tingkat pendidikan rendah 56 responden (93,3\%). Pengetahuan kurang sebanyak 43 orang (71,1\%). Faktor 
motivasi baik berjumlah 37 orang (61,7\%). Efikasi diri pasien DM tipe 2 kurang berjumlah 31 orang $(51,7 \%)$.

Tabel 2 Hasil Analisis Hubungan Usia, Jenis Kelamin, Lama Menderita, Tingkat Pendidikan, Pengetahuan, dan Motivasi dengan Efikasi Diri Pasien DM Tipe 2 di RSUD A.W. Sjahranie Samarinda $(n=60)$

\begin{tabular}{|c|c|c|c|c|c|c|c|c|}
\hline \multirow{3}{*}{ Variabel } & \multicolumn{4}{|c|}{$\begin{array}{c}\text { Efikasi Diri Pasien DM Tipe } \\
2\end{array}$} & \multicolumn{2}{|c|}{ TOTAL } & \multirow{3}{*}{$\begin{array}{c}\text { OR } \\
(95 \% \mathrm{Cl}) \\
\end{array}$} & \multirow{3}{*}{$\begin{array}{c}P \\
\text { Value }\end{array}$} \\
\hline & \multicolumn{2}{|c|}{ Kurang } & \multicolumn{2}{|c|}{ Baik } & & & & \\
\hline & $\begin{array}{c}n \\
(31)\end{array}$ & $\%$ & $\begin{array}{c}n \\
(29)\end{array}$ & $\%$ & $\begin{array}{c}n \\
(60)\end{array}$ & $\%$ & & \\
\hline \multicolumn{9}{|l|}{ Usia : } \\
\hline$<56$ tahun & 19 & 61,3 & 14 & 48,3 & 33 & 55 & 0,58 & 0,45 \\
\hline$\geq 56$ tahun & 12 & 38,7 & 15 & 51,7 & 27 & 45 & $(0,21-1,64)$ & \\
\hline \multicolumn{9}{|l|}{ Jenis Kelamin : } \\
\hline Laki-laki & 10 & 32,3 & 13 & 44,8 & 23 & 38,3 & 0,58 & 0,46 \\
\hline Perempuan & 21 & 67,7 & 16 & 55,2 & 37 & 61,7 & $(0,20-1,67)$ & \\
\hline \multicolumn{9}{|c|}{ Lama Menderita } \\
\hline \multicolumn{9}{|c|}{$\mathrm{DM}:$} \\
\hline$\geq 9$ tahun & 3 & 9,7 & 14 & 48,3 & 17 & 28,3 & 8,71 & 0,002 \\
\hline$<9$ tahun & 28 & 90,3 & 15 & 51,7 & 43 & 71,7 & $(2,15-35,17)$ & \\
\hline \multicolumn{9}{|l|}{ Tingkat } \\
\hline \multicolumn{9}{|l|}{ Pendidikan : } \\
\hline Tinggi & 1 & 3,2 & 3 & 6,7 & 4 & 6,7 & 3,46 & 0,34 \\
\hline Rendah & 30 & 96,8 & 26 & 89,7 & 56 & 93,3 & $(0,33-35,34)$ & \\
\hline \multicolumn{9}{|l|}{ Pengetahuan: } \\
\hline Kurang & 25 & 80,6 & 18 & 62,1 & 43 & 71,7 & 2,54 & 0,19 \\
\hline Baik & 6 & 19,4 & 11 & 37,9 & 17 & 28,3 & $(0,79-8,16)$ & \\
\hline \multicolumn{9}{|l|}{ Motivasi : } \\
\hline Kurang & 10 & 32,3 & 13 & 44,8 & 23 & 38,3 & 0,58 & 0,46 \\
\hline Baik & 21 & 67,7 & 16 & 55,2 & 37 & 61,7 & $(0,20-1,67)$ & \\
\hline
\end{tabular}

* signifikan pada $\alpha=0,05$

Hasil uji statistik hubungan usia dengan efikasi diri pasien DM tipe 2 menunjukkan bahwa tidak ada hubungan yang signifikan antara usia dengan efikasi diri pasien DM tipe 2 ( $p$ value $=0,45 ; \alpha=$ 0,05). Merujuk pada nilai OR, dapat disimpulkan bahwa responden dengan usia $\geq 56$ tahun berpeluang 0,58 kali menunjukkan efikasi diri yang baik dibandingkan dengan responden dengan usia <56 tahun (95\% Cl: 0,21;1,64). 
Hasil uji statistik hubungan jenis kelamin dengan efikasi diri pasien DM tipe 2 menunjukkan bahwa tidak ada hubungan yang signifikan antara jenis kelamin dengan efikasi diri pasien DM tipe 2 ( $p$ value $=0,46 ; \alpha=0,05$ ). Berdasarkan nilai $\mathrm{OR}$, responden yang berjenis kelamin perempuan memiliki peluang 0,58 kali menunjukkan efikasi diri yang baik dibandingkan dengan responden berjenis kelamin laki-laki $(95 \% \mathrm{Cl}: 0,20 ; 1,67)$.

Hasil uji statistik hubungan lama menderita diabetes melitus tipe 2 dengan efikasi diri pasien DM tipe 2 menunjukkan bahwa ada hubungan yang signifikan antara lama menderita diabetes melitus tipe 2 dengan efikasi diri pasien DM tipe 2 ( $p$ value $=0,002 ; \alpha=$ $0,05)$. Merujuk pada nilai OR, dapat disimpulkan bahwa responden yang menderita diabetes melitus tipe $2<9$ tahun berpeluang 8,71 kali menunjukkan efikasi diri yang baik dibandingkan dengan responden yang menderita diabetes melitus tipe $2 \geq 9$ tahun $(95 \% \mathrm{Cl}$ : $2,15 ; 35,17)$.

Hasil uji statistik hubungan tingkat pendidikan dengan efikasi diri pasien DM tipe 2 menunjukkan bahwa tidak ada hubungan yang signifikan antara tingkat pendidikan dengan efikasi diri pasien DM tipe 2 ( $p$ value $=0,34 ; \alpha=0,05)$. Berdasarkan nilai OR, responden yang tingkat pendidikannya rendah memiliki peluang 1,15 kali menunjukkan efikasi diri yang baik dibandingkan dengan responden dengan tingkat pendidikannya tinggi $(95 \% \mathrm{Cl}: 0,33 ; 35,34)$.

Hasil uji statistik hubungan pengetahuan dengan efikasi diri pasien DM tipe 2 menunjukkan bahwa tidak ada hubungan yang 
signifikan antara pengetahuan dengan efikasi diri pasien DM tipe 2 ( $p$ value $=0,19 ; \alpha=0,05$ ). Merujuk pada nilai OR, dapat disimpulkan bahwa responden yang berpengetahuan kurang berpeluang 2,54 kali menunjukkan efikasi diri yang baik dibandingkan dengan responden yang berpengetahuan baik $(95 \% \mathrm{Cl}: 0,79-8,16)$.

Hasil uji statistik hubungan motivasi dengan efikasi diri pasien DM tipe 2 menunjukkan bahwa tidak ada hubungan yang signifikan antara motivasi dengan efikasi diri pasien DM tipe 2 ( $p$ value $=0,46 ; \alpha=0,05)$. Berdasarkan nilai $O R$, responden yang motivasinya baik memiliki peluang 0,51 kali menunjukkan efikasi diri yang baik dibandingkan dengan responden yang motivasinya kurang (95\% Cl: 00,20-1,67).

Pada penelitian ini usia responden termuda adalah 37 tahun sedangkan usia tertua adalah 65 tahun. Hasil penelitian ini didukung oleh hasil penelitian Rabrusun (2015) tentang hubungan antara usia dan IMT dengan kejadian DM tipe 2, menunjukkan bahwa orang yang berumur $\geq 45$ tahun berisiko 1,690 kali lebih besar menimbulkan kejadian DM tipe 2. Peningkatan kejadian pada rentang usia tersebut berhubungan dengan indeks massa tubuh. Menurut Mansjoer (2005), penderita DM yang tergolong usia pertengahan/middle age (45 - 49 tahun), keadaaan pembuluh darah relatif masih baik, tetapi diperlukan pemantauan yang rutin guna mengantisipasi terjadinya penyakit perifer arterial (PAD). Teori lainnya mengatakan bahwa kejadian kasus baru dengan DM tipe 2 biasanya diatas 30 tahun dan sebagian besar karena obesitas 
(deWit \& Kumagai, 2013).

Hasil penelitian ini sejalan dengan hasil penelitian Masi (2016) yang menunjukkan bahwa jenis kelamin perempuan sebesar $56,3 \%$ dan laki-laki 43,8\%. Hasil penelitian sebelumnya oleh Pratomo (2014) dimana responden dengan jenis kelamin perempuan sebesar $63,3 \%$ dan laki-laki $36,7 \%$. enis kelamin perempuan dengan kejadian DM tipe 2 memiliki keterkaitan hubungan yang jelas. Faktor obesitas dan hormonal dapat mempengaruhi metabolisme tubuh pada perempuan. Seorang perempuan yang telah mengalami menopause dapat mempengaruhi menurunnya hormon estrogen dan peningkatan hormon androgen termasuk testosterone dan dehydroepiandrosteron. Peningkatan testosterone dapat mempengaruhi terjadinya peningkatan resistensi insulin dan meningkatkan kadar gluosa (Kim, 2012). Selain itu juga kondisi gestasional DM beresiko 20-50\% menderita DM tipe 2 pada 5 hingga 10 tahun kemudian (Jones, 2014).

Hasil penelitian ini menunjukkan sebagian besar responden telah menderita diabetes melitus $<9$ tahun $(71,7 \%)$. Hasil ini didukung oleh penelitian oleh Setyorini \& Wulandari (2017) yang menunjukkan bahwa sebagian besar responden sebanyak 59 orang (59\%) menderita DM tipe $2>5$ tahun. Penelitian relevan lainya dimana distribusi terbanyak pada durasi 6-10 tahun sebanyak 32 orang (36\%). Lamanya menderita DM menunjukkan bahwa penderita DM yang taat terhadap regimen pengobatan dan melaksanakan pola hidup sehat serta mampu beradaptasi dengan 
baik

Hasil penelitian ini relevan dengan penelitian Masi (2016) dimana responden yang berpendidikan rendah (SD, SMP, dan SMA) sebesar 69,8\% dan yang berpendidikan tinggi (PT) sebesar 30,2\%. terhadap penyakitnya, sehingga memiliki angka mortalitas yang rendah Restada (2016). pada tingkat pendidikan yang lebih rendah, akses seseorang untuk memperoleh informasi terkait kesehatan menjadi minimal, sehingga sering tidak menyadari gejala awal DM tipe 2. Responden yang berpendidikan menengah menunjukkan bahwa responden tersebut telah mampu memahami perkembangan ilmu pengetahuan dan teknologi terkait dengan kesehatan khususnya mengenai DM tipe 2.

Pengetahuan dalam penelitian ini terkait dengan pengetahuan dasar responden tentang penyakit DM tipe 2 . Rendahnya pengetahuan seseorang tentang pendidikan kesehatan dihubungkan dengan kesadaran terutama dalam kesehatan. Semakin rendah kesadaran dalam kesehatan akan menyebabkan semakin buruknya status kesehatan, hal ini disebabkan kecendrungan tidak mengetahui gejala-gejala penyakit DM dan tidak mengetahui deteksi dini penyakit DM tipe 2.

Hasil ini sejalan dengan penelitian Risti \& Isnaeni (2017) bahwa terdapat 27 responden (51,9\%) mempunyai motivasi diri yang baik, sedangkan sebanyak 25 responden $(48,1 \%)$ dengan motivasi yang tidak baik. Pada prinsipnya motivasi diri berasal dari diri sendiri, namun banyak faktor yang mempengaruhinya. 
Seseorang yang memiliki motivasi yang tinggi, dia akan berusaha untuk mewujudkan keinginannya. Motivasi yang tinggi juga mampu mempengaruhi pikirannya sendiri untuk mencari informasi terkait peningkatan status kesehatan atau upaya pencegahan penyakit. Apabila motivasi tersebut diaplikasikan akan membentuk suatu perilaku, dan bila berhasil individu yang bersangkutan akan merasa puas (Notoatmodjo, 2010). Motivasi adalah sesuatu yang mendorong seseorang untuk bertingkah laku guna mencapai tujuan tertentu (Saam \& Wahyuni, 2013). Lina (2013) memaparkan bahwa motivasi dapat memberikan pengaruh terhadap efikasi diri pasien DM Tipe 2 dalam perawatan diri.

Hasil ini menggambarkan bahwa pasien DM tipe 2 memiiki keyakinan diri yang kurang dalam mengontrol kadar gula darahnya. Hal ini relevan dengan penelitian sebelumnya oleh Rias (2016) bahwa sebagian besar efikasi diri cukup sebanyak 15 responden (50\%), efikasi diri kurang sebanyak 14 responden (47\%), dan efikasi diri baik sebanyak 1 responden (3\%). Seseorang dengan efikasi diri yang kurang disebabkan pengetahuan responden yang minim tentang penyakit DM tipe 2 serta kepercayaan yang belum optimal.

Usia responden tidak terlalu mempengaruhi efikasi diri dimana pada semua tahapan usia memiliki tugas dan perkembangan masing-masing, maka akan cenderung mengalami masalah dalam setiap tahapan usia terutama mengenai pengelolaan diabetes mellitus. Hal ini mendorong individu untuk mencapai efikasi diri yang baik guna meningkatkan kemampuan 
dalam pemecahan masalah kesehatan. baik perempuan atau lakilaki memiliki peluang yang sama dalam meningkatkan efikasi diri yang baik oleh karena jumlah responden perempuan memang lebih besar dibandingkan laki-laki. Setiap individu baik perempuan dan laki-laki memiliki tantangan yang sama dalam melakukan manajemen diabetes di kehidupan sehari-hari. Lamanya menderita DM tipe 2 berarti memiliki pengalamn hidup yang lama juga terhadap penyakit kronis sehingga dapat memberikan petunjuk bagi individu untuk menglola ketidaknyamanan fisik dan emosional (Lou et al, 2015). Dengan demikian dapat disimpulkan dalam penelitian ini responden dengan durasi DM yang lama berpeluang menunjukkan efikasi diri yang baik. pendidikan SMA yang merupakan pendidikan tahap akhir untuk bisa melanjutkan ke pendidikan tinggi. Sehingga seseorang yang telah menyelesaikan pendidikan sampai tahap SMA sudah mampu untuk memahami perkembangan ilmu pengetahuan dan teknologi sehingga mampu meningkatkan keyakinan terhadap kemampuan diri untuk mengatasi situasi tertentu. dukungan dari isteri/suami atau anak dalam pengelolaan DM responden, sehingga walaupun responden memiliki pengetahuan yang kurang dapat menunjukkan efikasi diri yang baik.

Responden dengan motivasi baik juga dapat menunjukkan efikasi diri yang baik maupun kurang. rasa takut akan komplikasi Diabetes Melitus sehingga rasa takut ini sangat kuat memberikan motivasi intrinsik yang mendasari perubahan perilaku. Hal ini 
dibuktikan dengan respon yang ditunjukkan oleh responden saat pengambiln data dengan bertanya kepada peneliti tentang hal-hal yang berkaitan dengan DM yang mereka derita. Selain itu juga mereka mengatakan bahwa mereka ingin berumur panjang dan melihat perkembangan anak cucunya dan merasa takut akan komplikasi yang ditimbukan. Kondisi ini dibuktikan dengan lamanya menderita penyakit DM tipe 2. Motivasi merupakan kekuatan yang dapat menggerakkan seseorang dalam beraktivitas $\mathrm{dn}$ mempertahankan perilaku atau melakukan suatu perubahan (Butler, 2002).

Banyak faktor yang perlu dilakukan penelitian lebih mendalam terkait efikasi diri DM tipe 2 antara lain depresi, dukungan keluarga dan sosial serta strategi koping yang dimiliki pasien diabetes mellitus tipe 2 . Selain itu juga penelitian ini menggunkan kuesioner yang terdiri dari pernyataan dengan skala likert yang disajikan dalam bentuk pilihan sangat tidak setuju sampai sangat setuju dan pilihan sangat sesuai sampai sangat tidak sesuai, sehingga responden bisa menutupi hal sebenarnya dengan memilih pilihan skala yang tidak sesuai dengan keadaan yang sebenarnya.

\section{KESIMPULAN}

\section{DAFTAR PUSTAKA}
Lama menderita DM Tipe 2 merupakan faktor yang berhubungan dengan efikasi diri pasien DM Tipe 2 dibandingkan dengan faktor usia, jenis kelamin, pendidikan, pengetahuan dan motivasi.

Bandura, A. (2007). Self efficacy in health functioning. Cambridge 
handbook of psychology, health \& medicine ( $\left.2^{\text {nd }} e d.\right)$. New York: Cambridge University Press

Bandura, A. (1997). Self efficacy : encyclopedia of human behavior. New York: Cambridge University Press (4) 71-81.

Baumann, C. L., \& Dang, N. T. T. (2012). Helping patients with chronic conditions overcome barriers to self-care. The NursePracticionero 37(3), 32-38. doi 10.1097/01.NPR.00004111.04.12617.64

Black, J. M., \& Hawks, J. H. (2009). Medical surgical nursing clinical management for positive outcome. eighth edition, Elsevier, St. Louis.

Butler, A. H. (2002). Motivation: The role in diabetes self management in older adult. UMI. www. searchproquest.com.

deWit, S. C., \& Kumagai, C. (2013). Medical-surgical nursing; consepts \& practice. St. Louis, Elsevier

Díaz, M.D., Herrington, W., M.D., Cervantes, M.L Ph.D.,Gnatiuc,L., M.Sc., Ramirez, R. Michael Hill, D.Phil., Colin Baigent, F.R.C.P., Mark I. McCarthy, M.D., Sarah Lewington, D.Phil., Rory Collins, F.R.S., Gary Whitlock, Ph.D., ${ }^{*}$ Roberto Tapia-Conyer, Ph.D., Richard Peto, F.R.S., Pablo Kuri-Morales, M.D., and Jonathan R. Emberson, Ph.D. Diabetes and Cause-Specific Mortality in Mexico City Th $e$ new england journal of medicine engl $j$ med 375;20 nejm.org Diunduh dari http://proquest.umi.com/pqdweb

Efendi, F \& Makhfudli. (2009). Keperawatan kesehatan komunitas. Jakarta: Salemba Medika.

Fisher, A.W., Cornman, H. D., Kohut, T., Schachner, H. (2013). What primary care providers can do to address barriers to selfmonitoring of blood glucose. Clinical Diabetes, 31(1), 34-42. Retrieved from htttp://searchproquest.com

Henderson, J., Wilson C., Roberts. L., Munt. R., Crotty. M.. (2014). Social barriers to Type 2 diabetes self-management: the role of capital. Nursing Inquiry 21: 336-345. doi: 10.1111/nin.12073

Huang, M., Zhao. R., Li. S., Jiang. X. (2014). Self-Management Behaviour in Patients with Type 2 Diabetes : A Cross- 
sectional Survey in Western Urban China. PLOS One, Vol.9(4)

Hunt, P. D. (2003). The concept of knowledge and how to measure

it. Journal of intellectual Capital, 4(1), 100-113. Doi 10.1108/14691930310455414

Jones (2014). Is Marital status a determinant of self monitoring blood glucose? A Thesis presented in partial fulfillment of requirements for the degree of Master of Science in the Department of Nutrition and Hospitality Management The University of Mississippi. www.searchingproquest.com

Kim, C (2012). does menopause increase diabetes risk? Strategies for diabetes prevention in midlife women. future medicine. woman health, 8(2), 155-167, doi; 10.2217/WHE.11.95.

Kott, K.B. (2008). Self-efficacy, outcome expectation, self-care behavior and glycosylated hemoglobin level in persons with type 2 diabetes. http://proquest.umi.com/pqdweb

Kozier, B., Erb, G., Berman, A., Snyder, J. S. (2010). Buku ajar fundamental keperawatan: konsep, proses dan praktik. Editor Dwi Widiarti. Jakarta. EGC

Lina (2013). Hubungan Motivasi Dengan Efikasi Diri Pasien DM Tipe 2 Dalam Melakukan Perawatan Kaki Di Wilayah Kerja Puskesmas Ponorogo Utara. URL https://de.scribd.com/doc/296394990/Jkptumpo-GdlFakultasil-753 11-Linaema. Di akses 3 november 2018

Lou, X., Liu. T., Yuan. X., Ge. S., Yang. J., Li. Ch., Sun. W (2015). Factor influencing self-management in Chinese adults with type 2 diabetes : A systematic review and meta-analisis. International Journal of Environ Research and Public Health, Vol 12, 11304-11327. doi: 10.3390/ijerph120911034.

Maghfirah, S. dkk. (2015). Relaksasi otot progresif terhadap stress psikologis dan perilaku perawatan diri pasien diabetes mellitus tipe 2. http://journal.unnes.ac.id

Mansjoer, Arief, dkk, 2005, Kapita Selekta Kedokteran Jilid 1, Media Aesculapius, Jakarta.

Masi, Gresty, N. (2016). Hubungan Motivasi Melakukan Self Monitoring Blood Glucose Dengan Diabetes Self Management Pada Pasien DM Tipe 2. (Tesis tidak dipublish). Universitas Indonesia

Notoatmodjo, S., 2010, IImu Perilaku Kesehatan, Rineka Cipta, 
Jakarta.

Nuari, N. A. (2014). Analisis Korelasi Personal Factor, Perceived Benefit Dan Perceived Barrier Dengan Pemberdayaan Diri Pasien Diabetes Mellitus Tipe li Berbasis Teori Health Promotion Model. Jurnal Gaster Vol. XI No. 2 Agustus 2014. http://download.portalgaruda.org/article.php. Diakses tanggal 20 oktober 2018.

PERKENI. (2011). Konsensus: pengelolaan dan pencegahan diabetes mellitus tipe 2 di Indonesia. http://www.perkeni.org/

Perry, A.G., \& Potter, P.A. (2004). Clinical nuring skilss techniques. ( $4^{\text {th }}$ Ed.). St.Louis: Mosby

Potter. P. A. \& Perry,A.G. (2008). Buku ajar fundamental keperawatan: Konsep, proses dan praktek. Jakarta: EGC

Pretsky, L. (2010). Principles of Diabetes Melitus. Second edition. Springer. New York. USA. Doi. 10.1007/978-0-378-09841-8

Price, S.A., \& Wilson, L.M. (2005). Patofisiologi konsep klinik prosesproses penyakit. Buku 2. Edisi 6. Jakarta : Penerbit Buku Kedokteran EGC

Restada, E.J. 2016. Hubungan Lama Menderita dan Komplikasi Diabetes Melitus dengan Kualitas Hidup pada Penderita Diabetes Melitus di Wilayah Puskesmas Gatak Sukoharjo.Skripsi. Program Studi S1 Keperawatan Fakultas Ilmu Kesehatan Universitas Muhammadiyah Surakarta

Saam, Z dan Wahyuni, S (2013). Psikologi Keperawatan. Rajawali Persada. Jakarta

Sastroasmoro, S., \& Ismael, S. (2014). Dasar-dasar metodologi penelitian klinis, ed 4. Jakarta: Sagung Seto

Scobie, N. I. (2015). Atlas of Diabetes mellitus, third edition. Informa healthcare. USA

Setiadi, 2013. Konsep Dan Praktik Penulisan Riset Keperawatan. Edisi 2. Graha Ilmu. Surabaya.

Siti Khuzaimah Ahmad Sharoni; Hejar Abdul Rahman; Minhat, Halimatus Sakdiah; Shariff-Ghazali, Sazlina; Mohd Hanafi Azman Ong. The effects of self-efficacy enhancing program on foot self-care behaviour of older adults with diabetes: A randomised controlled trial in elderly care facility, Peninsular Malaysia. PLoS One; San Francisco Vol. 13, Iss. 3, (Mar 2018): e0192417. 
Smeltzer, S, \& Bare. (2008). Brunner \& Suddarth's Textbook of medical surgical nursing. Philadelpia : Lippincott

Souza, V.D \& Zauseiniewski, J. A. (2005). Toward a theory of diabetes self-care management. Journal of Theory Construction \& Testing; Winter 2005/2006; 9,2. Diunduh dari http://proquest.umi.com/pqdweb

Stipanovic, A.R. (2003). The effects of diabetes education on selfefficacy and self care (Thesis master, University of Manitoba). University of Manitoba, Canada. Retrieved from http://proquest.umi.com/pqdweb

Suyono, S. (2010). Buku ajar ilmu penyakit dalam. (Edisi 3). Jakarta; Pusat penerbit Departemen Penyakit Dalam FKUI

Wagner, H. E., Austin, T. B., Davis, C., Hindmarsh, M., Schaefer, J., Bonomi, A. (2001). Improving chronic illness care: Translating evidence into action. Helath Affairs 20(6). 64-78. Doi 10.1377/hltaff.20.6.64.

Wantiyah, Sitorus, R., Gayatri, D. (2010). Faktor-faktor yang mempengaruhi efikasi diri pasien penyakit jantung koroner dalam konteks asuhan keperawatan di RSD dr. soebandi jember. Depok: FIK UI. Tesis tidak dipublikasikan.

Wu, S.F.V., Courtney, M., Edward, H., McDowell, J., ShortridgeBaggett, L.M., Chang, P.J. (2006). Self-efficacy, outcome expectation and self care behavior in people with type diabetes in taiwan. Diunduh dari 2010 dari http://web.ebscohost.com

Wu, S.F.V (2007). Effectiveness of self management for person with type 2diabetes following the implementation of a selfefficacy enhancing intervention program in taiwan. Queensland: Queensland University of Technology. Diunduh dari http://eprints.qut.edu.au/16385/1/Shu-

Fang_Wu_Thesis.pdf

Zuryati, Masmun. (2013). Tesis Hubungan Efikasi Diri dengan Kualitas Hidup Pasein DM Tipe 2 Di Rawat Inap Rumah Sakit Islam Jakarta Tahun 2013. Program Magister Keperawatan Fakultas IImu Keperawatan Universitas Muhammadiyah Jakarta 
